Silva, D. G. - (Re)criação do medievo em Cornelia Funke

\title{
Sobre "cavaleiras": a (re)criação do medievo em Cornelia Funke
}

\author{
[On female knights: the (re)creation of the medieval in Cornelia Funke] \\ http://dx.doi.org/10.11606/1982-883719291
}

\section{Daniele Gallindo Gonçalves Silva ${ }^{1}$}

\begin{abstract}
In the context of children's and young adult literature in contemporary German language, Cornelia Funke's production stands out. Born in Dorsten in 1958, the author - or, more specifically, the storyteller (Erzählerin), as she likes to be called -, brings together in the texts her ability as an illustrator. Since the worldwide success of the Tintenherz (Inkheart) trilogy, Funke became a successful figure in the children's and young adult universe. In most of her works there is the latent presence of the Western imaginary about the Middle Ages. However, that is a reception of the Middle Ages, either through the (re)creation of images or the (re)structuring of themes from the courtly universe. The article here proposed analyzes three works of Funke, namely Die geraubten Prinzen (1994), Igraine ohne Furcht (1998) and Der geheimnisvolle Ritter Namenlos (2001), taking as a starting point interviews of the author herself about this theme; in other words, it is the relationship between fact and fiction which will be considered. By focusing on the issue of the reinterpretation of the Middle Ages, this paper seeks to understand the reframing of the Middle Ages both through recreated images and the insertion of a new kind of hero, female protagonists.
\end{abstract}

Keywords: Cornelia Funke; children's and young adult literature; reception of the Middle Ages; feminine figures

Resumo: No âmbito da literatura infantil e juvenil em língua alemã contemporânea, destaca-se a produção de Cornelia Funke. Nascida em Dorsten em 1958, a autora - ou mais especificamente a contadora (Erzählerin), como gosta de se denominar -, acrescenta a seus textos a habilidade de ilustradora. Desde o sucesso mundial da triologia Tintenherz (Coração de tinta), Funke tornou-se uma personalidade de sucesso no universo infantil e juvenil. Em grande parte de suas obras, há a presença latente do imaginário ocidental acerca do medievo. Todavia, trata-se de uma recepção desse medievo, seja através da (re)criação de imagens ou da (re)estruturação de temáticas referentes ao universo cortês. O artigo aqui proposto analisa três obras de Funke, a saber: Die geraubten Prinzen (1994), Igraine ohne Furcht (1998) e Der geheimnisvolle Ritter Namenlos (2001), tendo como ponto de partida entrevistas da própria autora acerca do tema; ou seja, pensar-se-á a relação estabelecida entre o factual e o ficcional. Ao focar na questão da releitura do medievo, o artigo prentende compreender a ressignificação do medievo através tanto de imagens recriadas quanto da inserção de um novo tipo de herói, protagonistas femininas.

Palavras-chave: Cornelia Funke; literatura infantil e juvenil; recepção do medievo; personagens femininas

\footnotetext{
${ }^{1}$ Universidade Federal de Pelotas, Centro de Letras e Comunicação, Rua Gomes Carneiro, 01, Pelotas, RS, 96010-610, Brasil. E-mail: danigallindo@yahoo.de
} 
Silva, D. G. - (Re)criação do medievo em Cornelia Funke

\section{Introdução}

Cornelia Funke é atualmente considerada a mais aclamada escritora de literatura infantil e juvenil em língua alemã, sendo listada pela revista Time, ${ }^{2}$ em 2005, como uma das cem personalidades mais influentes do mundo, devido ao grande consumo de sua produção literária por crianças e por adultos (FREUND 2005). Todavia, Funke não iniciou sua carreira como escritora, mas sim como ilustradora. Contudo, por não se identificar com as histórias que ilustrava, optou por iniciar o processo de escrita. ${ }^{3}$

De acordo com a editora Dressler, responsável pela publicação dos livros de Funke na Alemanha, a autora escreveu cinquenta livros, traduzidos em 37 idiomas e publicados em 43 países. O sucesso internacional de Herr der Diebe e da Tintenherz-Trilogie culminou na adaptação desses para as telas, respectivamente The T(h)ief Lord (2006) e Inkheart (2008). ${ }^{4}$

As narrativas de Funke não se concentram apenas no mercado juvenil, como é o caso das obras anteriormente mencionadas; essas são as que, até o momento, chegaram ao Brasil através de traduções publicadas pela Companhia das Letras (selo Seguinte), sendo elas: $O$ senhor dos ladrões (2004, tradução de Sonali Bertuol), Coração de tinta (2006, tradução de Sonali Bertuol), O cavaleiro do dragão (2009, tradução de Sergio Tellaroli), Sangue de tinta (2009, tradução de Sonali Bertuol), Morte de tinta (2010, tradução de Carola Saavedra), A maldição da pedra (2011, tradução de Sonali Bertuol), O cavaleiro fantasma (2013, tradução de Laura Rivas Gagliardi), Sombras vivas (2013, tradução de Sonali Bertuol) e O fio dourado (2016, tradução de Sonali Bertuol). ${ }^{5}$ Há ainda toda uma gama de narrativas ilustradas voltadas para um público mais infantil, as quais ainda carecem de traduções para o português, ${ }^{6}$ sendo

\footnotetext{
${ }^{2}$ Para lista completa, ver <http://content.time.com/time/specials/packages/completelist/0,29569,1972656,00.html>. Acesso em: 6 ago. 2016. Sobre Cornelia Funke, ver <http://content.time.com/time/specials/packages/article/0,28804,1972656_1972696_1973413,00.html>. Acesso em: 6 ago. 2016.

${ }^{3}$ Informação retirada de <http://www.corneliafunke.com/index.php?page=cornelia_biografie\&lang=de>. Acesso em: 14 jul. 2016.

${ }^{4}$ Em relação à narrativa fílmica, resultante da adaptação de Tintenherz, Funke afirma reconhecer que, embora as personagens Basta e Capricórnio tenham características diferentes das imaginadas por ela, ao ceder suas obras a outros artistas, elas não a pertencem mais, tornando-se uma (re)criação do diretor (GASCHKE 2008). Neste sentido, é possível perceber a consciência da autora no que tange às adaptações de suas obras, pois compreende que uma transposição midiática nem sempre pode ser fiel ao original por inúmeros motivos.

${ }^{5}$ Para mais informações acerca das edições, acessar o site da editora:

〈http://www.companhiadasletras.com.br/autor.php?codigo=02095>. Acesso em: 6 ago. 2016.

${ }^{6}$ Sobre a recepção da obra de Cornelia Funke em inglês, cf. PICHLER (2011).
} 
Silva, D. G. - (Re)criação do medievo em Cornelia Funke

algumas dessas o foco de nossa análise nesse artigo: Die geraubten Prinzen (1994), Igraine ohne Furcht (2015 [1998]) e Der geheimnisvolle Ritter Namenlos (2001).

A finalidade desse recorte é pensar a recriação do medievo e a escolha narrativa de lançar mão de personagens femininas como protagonistas, embora em apenas uma delas esta centralidade esteja marcada já no título da obra, sendo as demais heroínas reveladas apenas no decorrer das tramas. Para tanto, as três obras serão analisadas levando em consideração, no que tange às releituras do medievo, dois níveis de interpretação: um sincrônico (o que as narrativas dizem sobre a atualidade) e outro anacrônico (o que eles constroem sobre o passado). No nível sincrônico, encontramos a presença do feminino como centro da obra; a jornada de heroínas (e não mais de heróis). Neste aspecto, analisaremos a construção dessas protagonistas, tendo como ponto de contato as jornadas de cavaleiros originários da literatura medieval, principalmente, elementos da épica cortês (Höfische Epik). ${ }^{7}$ No nível anacrônico, pensaremos a relação que a autora estabelece entre o passado construído no discurso historiográfico e o passado imaginado, seja em forma textual ou visual. Pensar esse anacronismo pressupõe, portanto, compreender a percepção da própria autora acerca do período medieval e, para tanto, a análise de excertos de entrevistas nos auxiliará nessa empreitada.

\section{A recepção do medievo}

O conceito Mittelalterrezeption contém sob sua tutela uma variedade de fenômenos, ou seja, podendo ser compreendido como um umbrella term (HERWEG; KEPPLER-TASAKI 2012: 2). Criou-se, assim, através da recepção, diversas imagens, por vezes bem distintas, que oscilam entre a "Idade das Trevas", principalmente no período que vai do Humanismo ao Iluminismo, e a "Idade Média romântica", um "tempo de uma visão de mundo unificada sem divisão religiosa e desunião moderna [...] uma era pré-industrial de harmonia do homem com a natureza"8 (MÄRTL 1997: 7). ${ }^{9}$ Neste sentido, Groebner afirma que "esta época [...] foi literalmente criada através de desejos, por mais de centenas de anos, e, desde então, ela é

\footnotetext{
${ }^{7} \mathrm{O}$ termo designa as produções que formalmente se apresentam em versos com rimas pares; têm como matéria a Antiguidade e a França; são o resultado da apropriação ou de traduções realizadas a partir de modelos dessas matérias e possuem, em sua maioria, autoria conhecida (BRANDT 1999: 204). Para mais informações da literatura produzida durante os séculos XII e XIII, ver BUMKE (2000).

${ }^{8}$ No original: "Zeit eines einheitlichen Weltbildes ohne religiöse Spaltung und moderne Zerrissenheit, [...] eine vorindustrielle Zeit der Harmonie des Menschen mit der Natur".

${ }^{9}$ Para um panorama detalhado da Mittelalterrezeption, cf. STEHLE (2012).
} 
Silva, D. G. - (Re)criação do medievo em Cornelia Funke

projetada, esboçada, equipada e mobiliada com os desejos" ${ }^{\prime 10}$ (GROEBNER 2008: 11). O conceito de Mittelalterrezeption engloba, assim, "uma visão positiva e uma negativa" "11 (OEXLE 1992: 7). Desta forma, pode-se defini-lo "não somente [como] percepção e representação da história, mas também [como] discussão e apropriação ou rejeição; portanto, [como] toda mediação e presentificação do passado"12 (KöHN 1991: 409).

Embora o período medieval não seja parte integrante de nosso passado, pensando-se aqui em relações temporais, ele ocupa nosso presente através do imaginário, de releituras e ressignificações dentro das mais variadas mídias. ${ }^{13}$ Analisar as diversas formas dessa recepção seria, portanto, compreender que o "passado se modifica de presente a] presente"14 (HerweG; KePPler-TASAKI 2012: 4). Todavia, lidaremos aqui com um tipo específico de recepção do medievo; aquele produzido dentro e pela literatura infantil e juvenil de Cornelia Funke.

De acordo com Funke, a Idade Média configura-se como o cenário ideal para a construção de histórias fantásticas, pois

[...] proporciona um bom pano de fundo para uma história, que joga com temas míticos e de contos de fada, pois muitos são oriundos dessa época, e, além disso, foi o período dos trovadores e livros iluminados, outros dois motivos importantes para minhas histórias. ${ }^{15}$ (ECKMANN-SCHMECHTA 2005, grifo nosso).

Embora o período medieval sirva para a grande maioria das obras de Funke como uma superfície de projeção para a construção de enredos e de personagens, a autora tem consciência de que, ao se falar em Idade Média, não se pode pressupor um único período temporal, "pois há nesse longo período de tempo épocas tão infinitamente diferentes como a

\footnotetext{
${ }^{10}$ No original: "[...] diese Epoche [...] ist buchstäblich durch Wünsche erschaffen worden, vor mehreren hundert Jahren und seither wird sie mit Wünsche entworfen, umrissen, ausgestattet und möbliert".

${ }^{11}$ No original: "[...] eine[ ] positive[ ] und eine[ ] negative[ ] Auffassung".

${ }^{12}$ No original: "[...] nicht nur [als] Wahrnehmung und Darstellung von Geschichte, sondern auch [als] Auseinandersetzung und Aneignung oder Ablehnung, demnach [als] jede Vermittlung und Vergegenwärtigung von Vergangenheit".

${ }^{13}$ Neste mesmo contexto, José Rivair Macedo, aponta para "duas formas de apropriação: as 'reminiscências medievais' e aquilo que, na ausência de melhor conceituação, denominamos de 'medievalidade" (MACEDO 2009: 15). Para Macedo, as reminiscências medievais englobam "as formas de apropriação dos vestígios do que um dia pertenceu ao Medievo, alterado e/ou transformados com o passar do tempo" (MACEDO 2009: 15). A medievalidade seria, portanto, quando "a Idade Média aparece apenas como uma referência, e por vezes uma referência fugidia, estereotipada" (MACEDO 2009: 16). Embora Macedo delimite e distinga essas duas formas de adaptação, sob a alcunha Mittelalterrezeption encontramos tanto esses quanto outros fenômenos, não somente na contemporaneidade, mas como um continuum histórico.

${ }^{14}$ No original: "Vergangenheit verändert sich von Gegenwart zu Gegenwart".

${ }^{15}$ No original: "[...] bietet einen guten Hintergrund für eine Geschichte, die mit Märchen-und Mythenmotiven spielt, weil viel aus dieser Zeit stammen, und außerdem war es die Zeit der Spielleute und illuminierten Bücher zwei weitere wichtige Motive für meine Geschichte."
} 
Silva, D. G. - (Re)criação do medievo em Cornelia Funke

Idade Média primeva e a tardia"16 (ECKMANN-SCHMECHTA 2005). Neste sentido, a Idade Média, e aqui falamos do potencial narrativo gerado pelas releituras possíveis desse período histórico, configura-se, para Funke, como uma época que exerce grande fascínio nos leitores. Assim, o período medieval e todas as imagens dele resultantes habitam não somente o imaginário dos leitores, mas também o da autora, pois esta afirma sonhar "com uma máquina do tempo" que visitaria "sobretudo os séculos XII e XIII"17 (BÖCKEM 2008).

Contudo, as imagens de Funke acerca do medievo estão longe de serem históricas, visto que, embora a autora, para a produção de suas narrativas, alegue ter pesquisado sobre a vida durante o período, tem consciência de que, em suas obras, se trata de uma recriação narrativa livre de qualquer compromisso com a historicidade. Nas palavras de Funke,

[...] eu li muito sobre a vida e, especialmente, a vida cotidiana na Idade Média, mas é claro que permanece sendo o mundo de Fenoglio, o qual não é idêntico à Idade Média real - para que eu pudesse tomar algumas liberdades. No entanto, a pesquisa me trouxe um monte de ideias e ajudou bastante a descrever a atmosfera deste mundo ${ }^{18}$ (ECKMANN-SCHMECHTA 2005, grifo nosso).

Pensar a relação entre real e ficcional é pressupor, sobretudo, que ao denominar uma "Idade Média real”, a autora remete à questão factual, ${ }^{19}$ ou seja, aos saberes construídos, em sua maioria, pela historiografia acerca do período: “[f]antasia é verdade, claro. Não é factual, mas é verdade"20 (LE GUIN 1993: 40). O acesso ao factual, no caso de Funke, nos é fornecido por intermédio das entrevistas, uma vez que, ainda que possamos compreender à que Idade Média a autora se refere, nos falta a bibliografia secundária por ela consultada. Sendo assim, falar do factual, nesse caso, é relacioná-lo também ao imaginário, pois, como afirmado por LE GoFF (2011: 13), a história do imaginário é "uma história da criação e do uso das imagens que fazem uma sociedade agir e pensar, visto que resultam da mentalidade, da sensibilidade e da

\footnotetext{
${ }^{16}$ No original: "[...] denn es gibt in diesem langen Zeitraum so unendlich verschiedene Zeiten wie das Früh-und das Spätmittelalter". Aqui vale uma ressalva: a terminologia alemã diferencia-se da francesa, comumente utilizada na academia brasileira, sendo a Idade Média primeva correspondente à Alta Idade Média.

${ }^{17}$ Trecho completo no original: "Ich träume von einer Zeitmaschine. Vor allem das 12. und 13. Jahrhundert würde ich gern besuchen". Vale ressaltar o período compreendido entre os séculos XII e XIII é o de maior produção de literatura cortês, seja em forma de épica (os considerados romances corteses) ou de lírica (o Minnesang).

${ }^{18}$ No original: "ich habe viel über das Leben und vor allem das Alltagsleben im Mittelalter gelesen, aber natürlich bleibt es Fenoglios Welt, die nicht identisch mit dem realen Mittelalter ist - so dass ich mir etliches an Freiheiten nehmen konnte. Dennoch hat mir die Recherche sehr viele Ideen gebracht und sehr geholfen, die Atmosphäre dieser Welt zu beschreiben".

${ }^{19}$ Neste sentido, Ankersmit afirma que "a luz de verdade da narrativa histórica é produzida por representações históricas do passado cuidadosamente construídas e intensamente discutidas" (ANKERSMIT 2012: 294).

${ }^{20}$ No original: "Fantasy is true, of course. It isn't factual, but it's true".
} 
Silva, D. G. - (Re)criação do medievo em Cornelia Funke

cultura que as impregnam e animam". Nas obras de Funke, portanto, o acesso aos universos medievais, às recriações, se estabelece na relação entre factual e imaginário. ${ }^{21}$

Essa conexão entre o factual e o ficcional fica bem explícita na fala de Fenoglio personagem da Tintenherz-Trilogie - quando este, ao chegar ao vilarejo medieval de Capricórnio - vilão da narrativa -, declara:

Sabe que este lugar é realmente muito parecido com um dos cenários que inventei para Coração de Tinta? Bem, aqui não há um castelo, mas a paisagem ao redor é praticamente a mesma, a idade da aldeia também deve bater mais ou menos. E você sabia que Coração de Tinta se passa num mundo que não é muito diferente da nossa Idade Média? Bem, naturalmente eu acrescentei algumas coisas, as fadas e os gigantes, por exemplo, e algumas coisas eu deixei de lado, mas... ${ }^{22}$ (FUNKE 2006: 275, grifo nosso).

Parece haver, portanto, na percepção da personagem uma diferenciação entre o factual, aquele construído pela historiografia/arqueologia (Burg, Landschaft), e o ficcional, representado na literatura tanto medieval quanto pós-medieval (Feen, Riesen), principalmente nas recepções oriundas do século XIX edificadas pelo movimento romântico alemão. Esta questão já havia sido apontada por Funke, quando afirma que:

Tudo aquilo que eu tinha operado em investigação foi apenas Idade Média, e, é claro, nossa concepção de Idade Média! Isso eu também notei, quando me ocupei com o século XIX e observei os pré-rafaelitas - que tudo é uma Idade Média glorificada. [...] Eu acho que é um terrível mau hábito glorificar tempos antigos. Mas a tendência humana de construir tudo, que podemos construir, e, em seguida, sentar-se com um brinquedo perigoso e lidar com isso tão irresponsavelmente como uma criança pequena; essa mistura de gênio humano e irresponsabilidade humana continua a ser assustadora ${ }^{23}$ (SPRECKELSEN 2010, grifo nosso).

Do excerto acima, podemos depreender que, de acordo com a autora, há, no mínimo, duas imagens recorrentes do medievo: uma construída através de pesquisa, e que, portanto, se aproximaria mais do real, e outra, construída dentro de uma base ideológica; aqui o recorte

\footnotetext{
${ }^{21}$ Iser propõe uma discussão acerca da relação estabelecida entre o real, o fictício e o imaginário. Todavia, sua conceitualização e aplicação dos termos são de outra ordem da daqui utilizada. Para o autor, "o real é compreendido como o mundo extratextual, que, enquanto faticidade, é prévio ao texto e que ordinariamente constitui seus campos de referências" (ISER 2002: 985).

${ }^{22}$ No original: "Weißt du, dass dieser Ort einem der Schauplätze, die ich für Tintenherz erfunden habe, durchaus ähnlich sieht? Nun gut, es gibt keine Burg, aber die Landschaft ringsum ist annähernd die gleiche, und das Alter des Dorfes dürfte auch fast hinkommen. Und weißt du, dass Tintenherz in einer Welt spielt, die unserem Mittelalter nicht ganz unähnlich ist? Gut, ich habe natürlich einiges hinzugefügt, die Feen und Riesen zum Beispiel, und einiges habe ich weggelassen, aber...” (FUNKE 2010: 340, grifo nosso).

${ }^{23}$ No original: "Alles, was ich dafür an Recherche betrieben hatte, war immer nur Mittelalter, und natürlich: unser Begriff von Mittelalter! Das habe ich dann auch gemerkt, als ich mich mit dem 19. Jahrhundert beschäftigte und mir die Präraffaeliten anschaute - das ist ja alles schon verklärtes Mittelalter. [...] Ich finde es eine furchtbare Unart, ältere Zeiten zu verklären. Aber die menschliche Tendenz, alles zu bauen, was wir bauen können und dann mit einem gefährlichen Spielzeug dazusitzen und damit so verantwortungslos umzugehen wie ein Kleinkind - diese Mischung aus menschlichem Genie und menschlicher Verantwortungslosigkeit bleibt erschreckend."
} 
Silva, D. G. - (Re)criação do medievo em Cornelia Funke

temporal é o século XIX e sua “Idade Média glorificada”. Funke alerta, ainda, para os perigos do uso "irresponsável" do passado. Neste momento, podemos depreender que a autora se refere a épocas em que acontecimentos históricos foram instrumentalizados para fins outros, por exemplo, fins políticos de legitimação ideológicas. ${ }^{24}$

Ainda no que se refere ao século XIX, e principalmente acerca das produções literárias denominadas Märchen, ${ }^{25}$ a autora assevera, em relação à figura feminina, que:

Foi uma das minhas experiências mais importantes constatar, durante o trabalho em Reckless, que os ideais burgueses trazem consigo uma imagem específica de mulher. Interessante é que a imagem de mulher na Idade Média era, em parte, mais rebelde e menos dogmática. Pensamos que esta se tornou cada vez melhor ao longo dos anos. Eu temo que não seja assim ${ }^{26}$ (Cossham 2013, grifo nosso).

Nesse sentido, o século XIX parece ter criado, através de recepções, uma imagem de medievo que pouco dialoga com a historiografia: uma Idade Média construída com base no desenvolvimento da Filologia bem como gerada pela idealização de intelectuais para o fomento à unificação. ${ }^{27} \mathrm{~A}$ ideia de recepção do medievo parece ficar bem nítida na percepção de Funke acerca da figura feminina, pois de um lado encontra-se a figura feminina do século XIX e do outro sua contraparte medieval. Desta forma, percebemos claramente o percurso de pesquisa da autora e a conclusão de que, para a Alemanha, essas duas imagens de medievo possibilitam, no mínimo, a seguinte reflexão: de que Idade Média se fala quando o tema é recepção?

Precisamos, ainda, elucidar o que configuraria o conceito de Idade Média para a autora, o qual ela denomina unser Mittelalter, termo reiterado tanto em entrevista quanto nas palavras de sua personagem Fenoglio. Funke parece apontar em suas entrevistas tanto para um lado positivo quanto para uma percepção negativa no que concerne ao período medieval. O passado, em comparação com o presente, é colocado como uma época obscura e de miséria, mas que, ainda assim, tem a capacidade de fascinar. De acordo com Funke:

A vida era mais difícil, mas as pessoas sabiam mais sobre a vida e a morte, sobre o ritmo da natureza, elas se sentiam muito mais conectadas com os planetas, no qual viviam, para melhor ou para pior, e, em muitos aspectos, as estruturas e regras eram consideravelmente mais

\footnotetext{
${ }^{24}$ Vale lembrar o caso da apropriação da Nibelungenlied durante o período entre Guerras (SILVA 2014).

25 Acerca do conceito de Märchen e seu histórico, ver PÖGE-ALDER (2011: 24-27).

${ }^{26}$ No original: "Es war eine meiner wichtigsten Erfahrungen, während meiner Arbeit an Reckless festzustellen, dass bürgerliche Ideale ein bestimmtes Frauenbild mit sich bringen. Spannend ist auch, dass das Frauenbild im Mittelalter teilweise rebellischer und undogmatischer war. Wir denken, dass es über die Jahre immer besser geworden ist. Ich fürchte, das ist nicht so."

${ }^{27}$ Sobre o romantismo alemão, ver SAFRANSKI (2009).
} 
Silva, D. G. - (Re)criação do medievo em Cornelia Funke

simples do que no nosso tempo - o que é um requisito maravilhoso para um contador de histórias. ${ }^{28}$

Funke aponta, portanto, para a Idade Média como um período histórico, no qual a humanidade estava conectada harmonicamente com a natureza e com o cosmos, em um ambiente "mais simples" tanto estruturalmente quanto no que se refere às regras: isso potencializaria a geração de histórias. Em outras palavras é afirmar que quando falamos de recepção do medievo, estaríamos, a priori, lidando com "a Idade Média em narração e a narrada, a literária [...] uma realidade gerada, virtual”29 (JÜRGS 2012: 179).

Entretanto, não são somente as narrativas de Funke que criam novas imagens desse período. De acordo com Ina KARG (2007: 158-161), a recepção do medievo na literatura infantil e juvenil pode se manifestar basicamente em quatro categorias: 1. "matérias e motivos" cujo pano de fundo é um acontecimento medieval" ${ }^{31}$ (exemplo: O nome da rosa, Umberto Eco), 3. "Fantasy-Literatur" (exemplo: A história sem fim, Michael Ende) e 4. "medieval, ou o que se julga ser, como ambiente divertido e com pano de fundo jocoso",32 (exemplo: Igraine, Cornelia Funke). Resta-nos, agora, adentrar o universo das três narrativas selecionadas para análise com a finalidade de se conhecer "como o processamento da matéria e do diálogo com o passado acontece e que função isto tem para conhecimentos também em cada atualidade"33 (KARG 2007: 177), focando na análise das personagens femininas e na recriação do universo medieval.

\section{Imagens do medievo em Funke}

As duas narrativas ilustradas - Die geraubten Prinzen (1994, ilustrações de Elisabeth Holzhausen, e 2014, ilustrações de Jörn Mühle) e Der geheimnisvolle Ritter Namenlos (2001,

\footnotetext{
${ }^{28}$ No original: "Das Leben war härter, aber die Menschen wussten mehr über Leben und Tod, über den Rhythmus der Natur, sie fühlten sich viel mehr mit dem Planeten verbunden, auf dem sie lebten, im Guten wie im Schlechten, und in vieler Hinsicht waren die Strukturen und Regeln wesentlich einfacher als in unserer Zeit was eine wunderbare Voraussetzung für einen Geschichtenerzähler ist”. Disponível em: <http://tbuecher.jimdo.com/interviews-1/cornelia-funke>. Acesso em: 16 jul. 2016.

${ }^{29}$ No original: “[...] das erzählende und erzählte, das literarische Mittelalter [...] eine generierte, virtuelle Realität".

${ }^{30}$ No original: "Stoffe und Motive".

${ }^{31}$ No original: "[...] historische Romane, deren Kulisse ein mittelalterliches Geschehen ist”.

${ }^{32}$ No original: "Mittelalterliches, oder was man dafür hält, als lustiges Ambiente und Klamauk-Kulisse".

${ }^{33}$ No original: "[...] wie die Bearbeitung des Stoffes und der Dialog mit der Vergangenheit erfolgt und welche Funktion dies für Einsichten auch in jeweils Gegenwärtiges hat”.
} 
Silva, D. G. - (Re)criação do medievo em Cornelia Funke

ilustrações de Kerstin Meyer) - e a narrativa juvenil - Igraine Ohnefurcht (2015 [1998], ilustrações de Cornelia Funke) - trazem representações oriundas do imaginário da literatura cortês medieval: reinos em perigo, a jornada de cavaleiros salvadores e torneios pela mão da donzela. Até mesmo a escolha das ilustrações se orienta pelo imaginário que se tem da Idade Média: castelos, reis, cavaleiros em armaduras, torneios. Como exemplo, destacamos as capas de duas das obras selecionadas para análise. Na primeira imagem (FIG. 1), encontra-se a representação de um cavaleiro, em uma cota de malha, empunhando uma espada. Há uma relação nítida com as representações de cavaleiros templários; todavia, no lugar da cruz vermelha visualiza-se um coração. Na segunda (FIG. 2), vê-se uma jovem, na ameia, vestida em armadura, espada embainhada e, embaixo do braço, um elmo com pavão no topo; próximo a ela um jovem traja uma túnica: aqui, as referências ao medievo são mais gerais do que na FIG. 1.

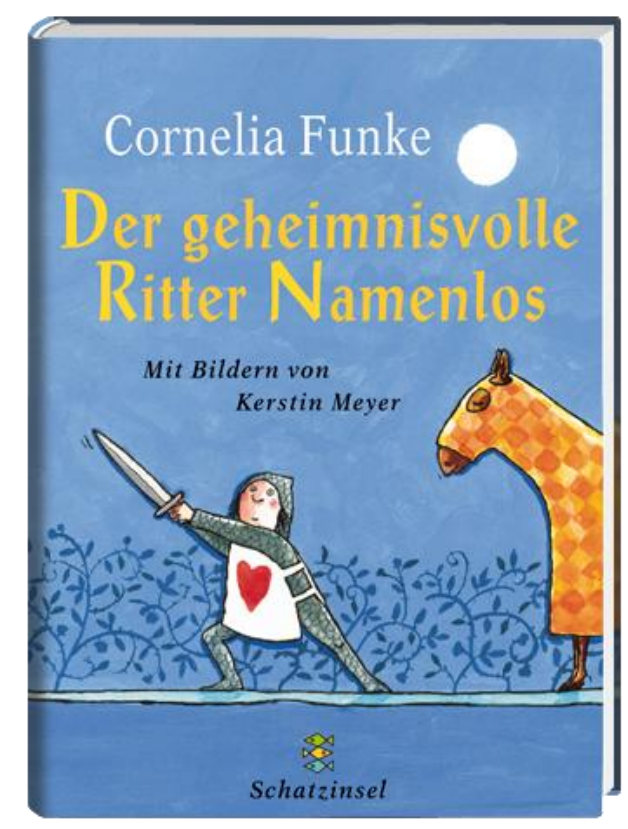

FIGURA 1 - Capa do livro Der geheimnisvolle Ritter Namenlos

Fonte:

<http://www.corneliafunke.com/index.php?page=bue cher_detail\&id=9\&lang=de >. Acesso em: 20 jul 2016.

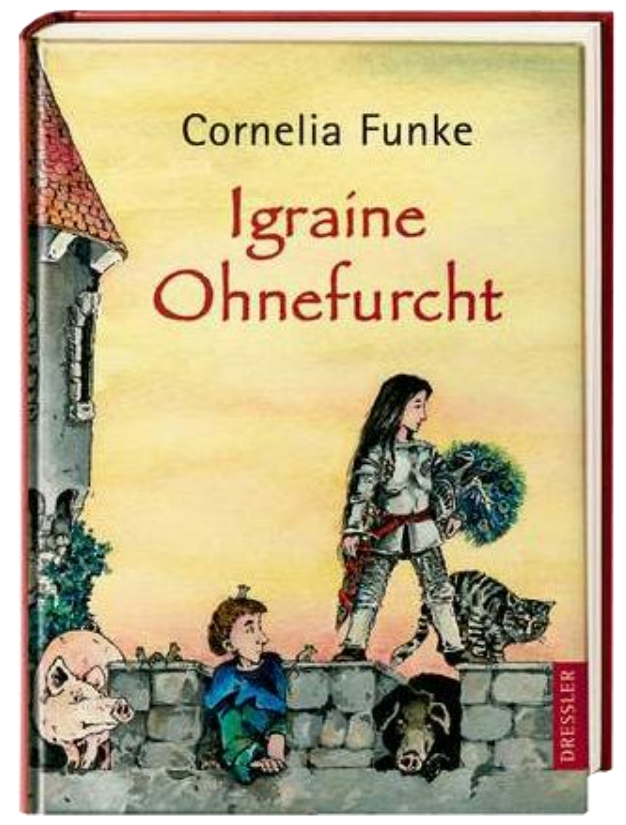

FIGURA 2 - Capa do livro Igraine Ohnefurcht Fonte:

<http://www.corneliafunke.com/index.php?page=bue cher detail\&id=27\&lang=de $>$. Acesso em: 20 jul. 2016.

A disposição gráfica de algumas das páginas de Der geheimnisvolle Ritter Namenlos remete às representações imagéticas contidas na Tapeçaria de Bayeux (cf. FIG. 3 e 4). Na tapeçaria do século XI, que mede "cerca de $70 \mathrm{~m}$ de comprimento e cerca de $50 \mathrm{~cm}$ de altura",34

\footnotetext{
${ }^{34}$ No original: "[...] ca. $70 \mathrm{~m}$ lange und ca. $50 \mathrm{~cm}$ hohe".
} 
Silva, D. G. - (Re)criação do medievo em Cornelia Funke

(SCHNITH 2003: 1712), está representada a invasão normanda à Inglaterra em $1066 .{ }^{35}$ As imagens, apresentadas sequencialmente, são acompanhadas de um pequeno trecho em latim. No livro de Funke, reproduz-se também a junção de imagens sequenciais e texto, embora a relação pareça ser inversa à da tapeçaria, visto que em Funke a base é o texto e na tapeçaria a base é a imagem. Todavia, ambas lidam com o apelo à visualidade.

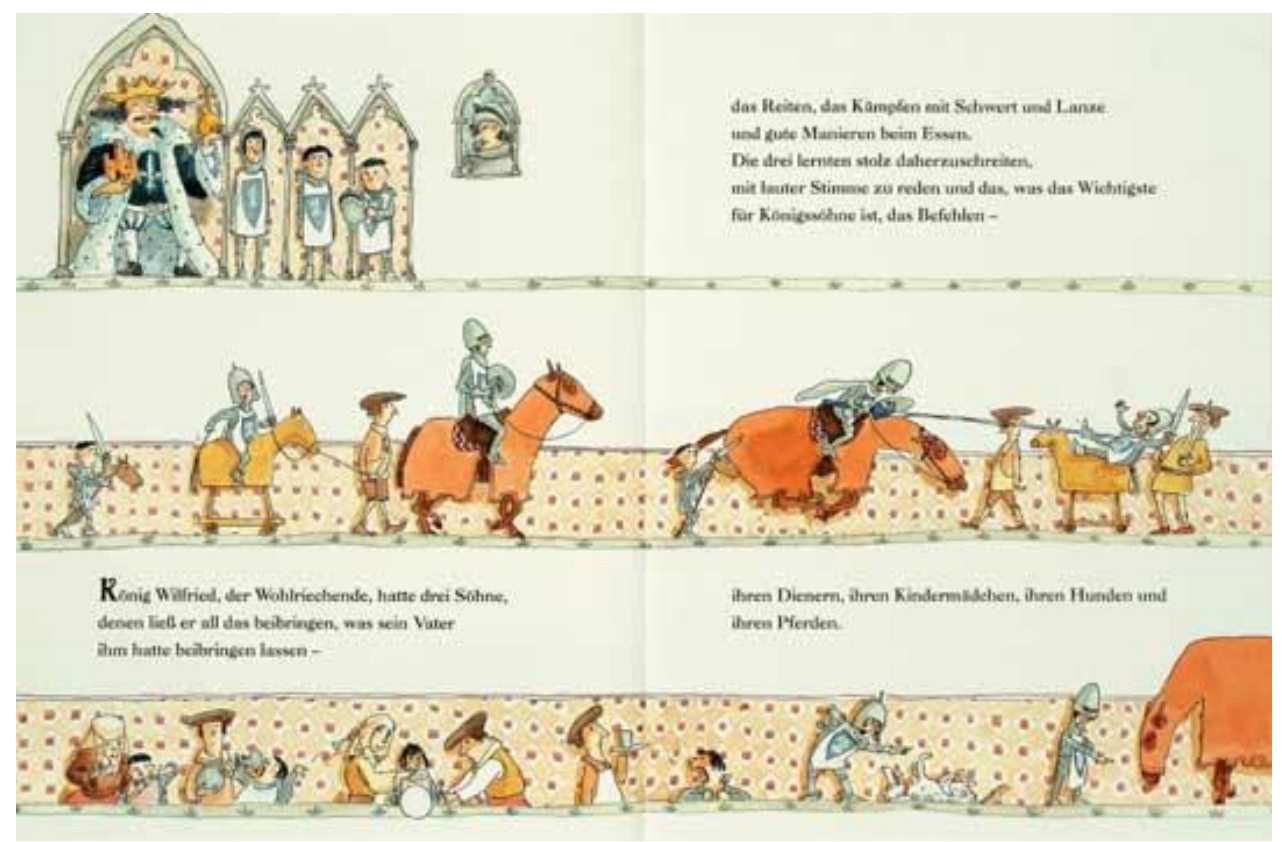

FIGURA 3 - Página de Der geheimnisvolle Ritter Namenlos

Fonte: FunKE 2001: 4-5. Disponível em:

$\langle$ http://www.fischerverlage.de/sixcms/detail.php?template=bilderbuch detail\&id=208769\&_pic=1 $>$. Acesso em: 20 jul. 2016.

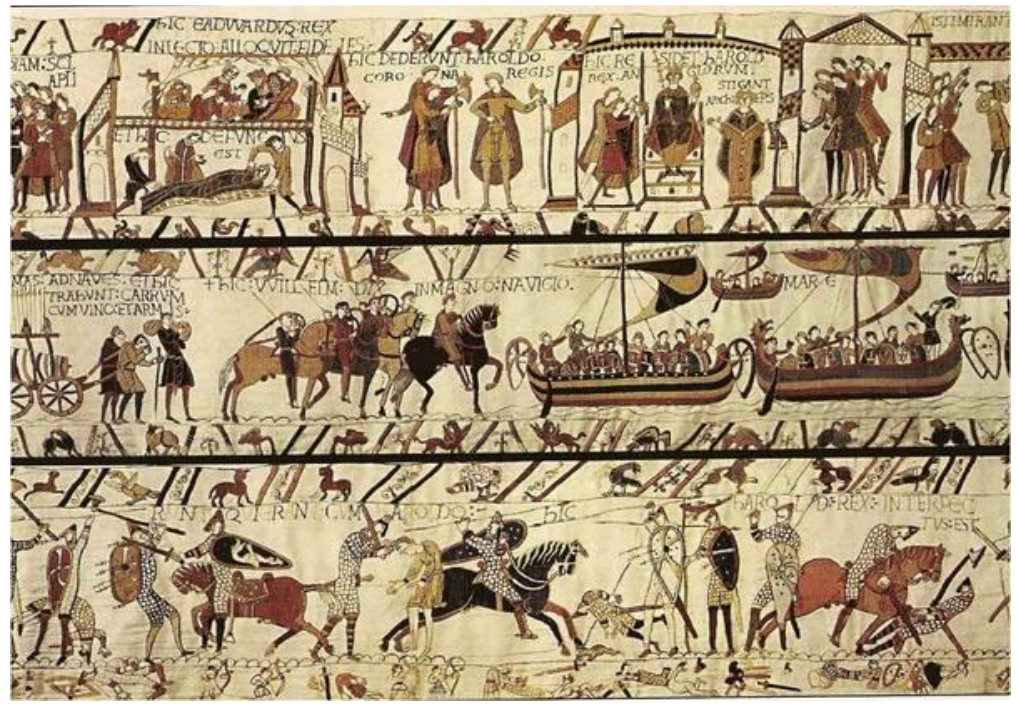

FIGURA 4 - Pisserie de Bayeux (ca. 1070)

Fonte: <http://lounge.obviousmag.org/anna_anjos/2013/08/a-tapecaria-bayeux.html >. Acesso em: 20 jul. 2016.

\footnotetext{
${ }^{35}$ Mais informações acerca do tema em LEWIS; OWEN-CROCKER; TERKLA (2011).
} 
Contudo, se na tapeçaria o protagonismo é masculino, nas três narrativas de Funke entram em cena figuras femininas. Há de perguntar-se, a priori, se as narrativas, ao inserirem protagonistas femininas no lugar das masculinas realmente utilizam um discurso contemporâneo em relação à construção dos gêneros ${ }^{36}$ ou, ainda, qual seria a representação destas nos textos.

Príncipes roubados de castelos por uma giganta, a qual os usa como bonecos para brincar; uma rainha - Adelheit - que recompensará com ouro quem regastar seu querido filho, esta é a trama central de Die geraubten Prinzen (1994b). O narrador, em terceira pessoa, apresenta ao leitor "uma terrível gigante chamada Grauseldis",37 (FUNKE 1994b: 26), o adjetivo e o nome próprio apontam para uma dupla definição da antagonista como "terrível", uma vez que Grauseldis relaciona-se com grausam. Todavia, a descrição de sua personalidade fica no nível da criação narrativa de uma tensão entre esta e a personagem principal: o cavaleiro vermelho, que ao se revelar mostra que é uma "Ritterin", Frieda Ohnefurcht, é "uma mulher muito bela"38 (FUNKE 1994b: 28). Antes da revelação parece haver um momento de hesitação por parte da rainha, pois o cavaleiro pede a mão do príncipe. Ao ter sua identidade revelada, contudo, a tensão se dissolve e a rainha aceita as condições propostas pela “cavaleira”. Frieda Ohnefurcht segue destemidamente para o confronto com a giganta. Não vence pela força, mas por astúcia, ao retirar de sua luva uma aranha e fazer com que Grauseldis paralise: "pedaço por pedaço petrificou [...], até ficar cinza e imóvel no saguão do castelo" 39 (FunKE 1994b: 32). No final da narrativa, escolhe seu par, que, todavia, não é o príncipe que havia salvo de Grauseldis.

A figura feminina da gigante, ainda que incorpore o inimigo a ser vencido, reproduz a imagem recorrente de feminino, que brinca com bonecas e guarda seus pertences mais estimados, aqui no caso os príncipes, em uma bolsa e depois em sua casa de bonecas. Sua imponência como gigante dista, entretanto, de sua fragilidade por temer aranhas: é vencida pela astúcia da “cavaleira”. Frieda, como seu nome já indica, é destemida; vitoriosa em muitas batalhas, ela personifica o herói salvador: uma heroína que, ao resgatar personagens masculinos em perigo, restaura a ordem de dinastias. Sua jornada remete às tramas das épicas

\footnotetext{
${ }^{36}$ Entendemos gênero como "um elemento constitutivo de relações sociais baseado nas diferenças percebidas entre os sexos, [...] uma forma primeira de significar as relações de poder" (SCOTT 1999: 42).

${ }^{37}$ No original: "[...] eine schreckliche Riesin namens Grauseldis".

${ }^{38}$ No original: "[...] eine wunderschöne Frau".

${ }^{39}$ No original: "[...] [s]tück für Stück erstarrte [...], bis sie grau und reglos in der Schlosshalle stand".
} 
Silva, D. G. - (Re)criação do medievo em Cornelia Funke

corteses medievais - citamos aqui como exemplo o Parzival, de Wolfram von Eschenbach, visto que o protagonista homônimo é conhecido como o cavaleiro vermelho -, pois naquelas os heróis envolvem-se na restauração de reinos sitiados e são premiados com a mão de donzelas.

Violetta - protagonista de Der geheimnissvolle Ritter Namenlos - perde a mãe no momento do parto, e, cercada por figuras masculinas (pai e três irmãos), aprende a manejar armas como seus irmãos. O rei decide criar a menina à maneira que lhe é conhecida, ou seja, como um rapaz: "E ninguém pode dizer ao rei o que se ensina a uma filha. Então, ele mandou ensiná-la o mesmo que a seus filhos" ${ }^{40}$ (FUNKE 2001: 7). Quebra-se aqui o paradigma de que a menina é ensinada pela figura materna a ser uma princesa, uma vez que Violetta é ensinada a manejar armas bem como a se portar como um cavaleiro. Contudo, repete-se a ideia de que há papéis femininos e masculinos que são passados através de gerações.

Por ser motivo de troça para os irmãos, pois é considerada pequena e mais fraca ("Spinnenbein, Mückenstark, Fliegenschreck" - FUNKE 2001: 9), ${ }^{41}$ Violetta decide que não vai desistir do treinamento, como aconselhada pela serviçal, Emma, a qual tem uma imagem muita clara do que é ser mulher: "Por que não pedis a vosso pai que vos ensinai outra coisa que não a miserável brigalhada? Aprendei a bordar ou tecer, a tocar flauta ou algo útil”,42 (FUNKE 2001: 13). Nesse trecho é nítida a distinção entre os papéis estabelecidos para personagens femininas e masculinas: a eles, a luta e o espaço público, a elas, os afazeres domésticos e o espaço privado, e mais uma vez cabe a uma figura mais velha a repetição de determinados valores (relacionados diretamente com as personagens femininas e masculinas da épica cortês).

Até o momento de se tornar uma adolescente, etapa marcada na narrativa pelo aniversário de 16 anos, Violetta é representada em trajes masculinos, mais especificamente, em armadura ou túnica de treinamento. A passagem de menina para moça é marcada visualmente através da troca da armadura - retirada com o auxílio do escudeiro - pelo vestido

\footnotetext{
${ }^{40}$ No original: "Und niemand konnte den König sagen, was man einer Tochter beibringt. Also ließ er sie dasselbe lernen wie seine Söhne".

${ }^{41}$ Há aqui similaridades entre a história de Violetta e a narrativa Der Namenlose Ritter (FUNKE 1994a), na qual a protagonista é Eleonore, a qual, cansada de ter que beijar os cavaleiros que vencem os torneios promovidos pelo seu pai, resolve 'lutar' pela própria mão e, ao final, se casa com o jardineiro de seu pai. Embora o nome das heroínas mude, o nome da figura paterna é o mesmo nas duas narrativas: "König Wilfred der Wohlriechende" (FUNKE 1994a: 18; 2001: 4).

${ }_{42}$ No original: "Warum bietet Ihr Euren Vater nicht, Euch etwas anderes lernen zu lassen als die elende Kämpferei? Lernt Sticken oder Weben, die Flöte spielen oder sonst etwas Nützliches”.
} 
Silva, D. G. - (Re)criação do medievo em Cornelia Funke

- colocado com o auxílio da serviçal Emma (FIG. 5). O espaço da passagem entre público, o cavaleiro, e privado, a dama, é representado pelo biombo.

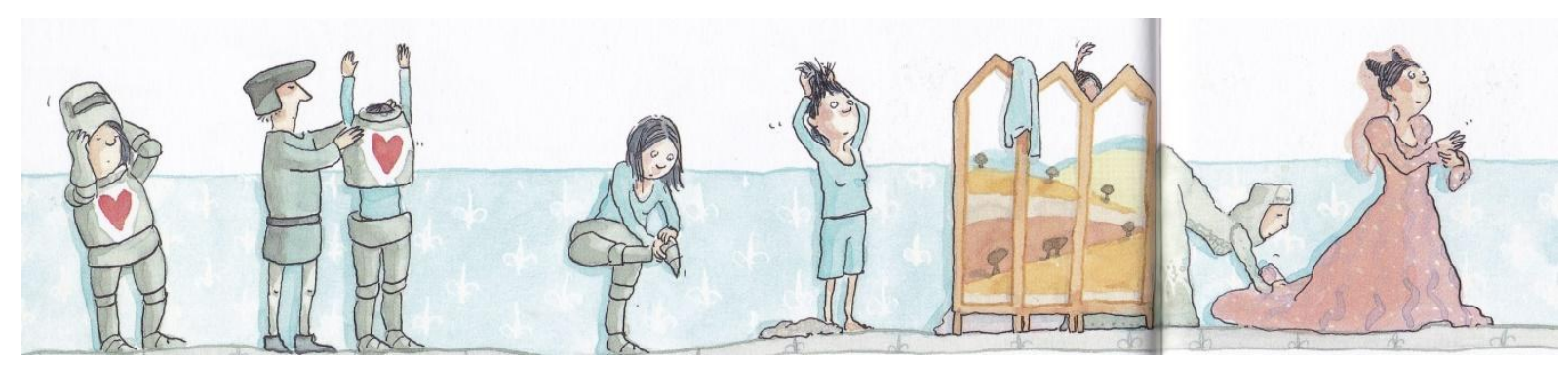

FIGURA 5 - Detalhe de ilustração em Der geheimnisvolle Ritter Namenlos

Fonte: FUNKE 2001: 18-19. Ilustração de Kerstin Meyer.

Quando a jovem está para completar 16 anos, o pai anuncia um torneio no qual o vencedor se casará com Violetta. Se até então o rei, aparentemente, não se importa que a jovem se vista e se comporte como um cavaleiro, ou seja, como seus irmãos meninos, a partir desse momento o pai exige que ela incorpore o papel de princesa: "Então, veste teu belo vestido e treine diante do espelho a sorrir simpaticamente"43 (FUNKE 2001: 19). Fica claro na narrativa que não somente ser cavaleiro requer exercício, mas também a cortesia feminina, aqui representada pelo sorriso, precisa ser exercitada, ou seja, não é uma característica inata ao comportamento da jovem. Entretanto, Violetta mostra-se descontente com a notícia e esbraveja: "Nunca casarei com um idiota. Reparai, pois, vossos cavaleiros! Eles espancam seus cavalos e são muito ignorantes para escrever seus nomes!" ${ }^{44}$ (FUNKE 2001: 20). ${ }^{45}$ A menina coloca-se, assim, em um lado oposto ao dos cavaleiros, quando os caracteriza como "ignorantes" por não saberem escrever: seu universo, ou o modelo por ela aceito, é, portanto, o cortês.

No dia do torneio, graças ao treinamento desgastante para fugir do deboche dos irmãos, a jovem vence todos os pretendentes e solicita ter o direito à própria mão: "Nenhum

\footnotetext{
${ }^{43}$ No original: "Also zieh dir dein schönes Kleid an und übe vor dem Spiegel freundlich zu lächeln".

${ }^{44}$ No original: "Niemals werde ich so einen Blechkopf heiraten. Seht euch doch Eure Ritter an! Sie prügeln ihre Pferde und sind zu dumm, ihren Namen zu schreiben!"

${ }^{45}$ Em Der Namenlose Ritter, Eleonore tem a mesma reação de revolta: "Sie [diese Ritter] stinken nach Rost und Schweiß und haben nichts im Kopf als ihre Schwerter und ihre Wappen. Schluss! Ich werde nie wieder einen dieser Blechköpfe küssen!” (FUNKE 1994a: 18).
} 


$$
\text { Silva, D. G. - (Re)criação do medievo em Cornelia Funke }
$$

cavaleiro jamais iria querer confrontar novamente o Sem-Nome. E Violetta se casou com o jardineiro de seu pai”,46 (FUNKE 2001: 30).

Ao analisarmos a fala de revolta de Violetta em relação ao comunicado do pai (FUNKE 2001: 20) e a decisão de casar-se como o jardineiro (FUNKE 2001: 30), podemos verificar que a narrativa apresenta dois modelos distintos de personagens masculinas: 1. a imagem do cavaleiro que se baseia no trabalho com o corpo (disciplina) e na aquisição da fama - modelo propagado em grande parte pelas épicas corteses medievais -, e 2. a imagem de um masculino sensível representado pelo jardineiro, o qual se apresenta claramente como um contra-modelo ao anterior: passado e presente entram em diálogo.

Destacamos também a construção de dois modelos de princesas: 1. femininos conectados ao espaço privado e que devem se casar - modelo propagado, principalmente, pelos Märchen, e que na narrativa aparece na decisão do pai de casar Violetta - e 2. femininos heróicos que lutam por seus direitos, modelo que vem sendo incorporado gradualmente pelas animações (cf. o filme Brave, 2012). Vemos, portanto, o encontro de modelos narrativos considerados consagrados com novas imagens de femininos e masculinos. Ao mesmo tempo em que na contracapa de Der geheimnissvolle Ritter Namenlos encontramos a menção ao primeiro modelo de princesa anteriormente referido ("Princesas não cavalgam nem lutam; princesas devem ter bela aparência e casar com cavaleiros corajosos"), ${ }^{47}$ também aponta-se para uma (des)construção desse modelo, quando em destaque aparece: "Meninas fortes sabem ajudar a si mesmas" ${ }^{48}$ É nesse segundo modelo que se situa Violetta, visto que ao optar por rejeitar a ajuda do irmão, uma figura masculina, decide tomar a rédea da situação e combater pelo direito ao seu próprio corpo, metonimizado pela entrega da mão da princesa ao vencedor do torneio.

As duas obras anteriormente analisadas são mais voltadas ao público infantil (“ab 3 Jahren"), tendo a próxima - Igraine Ohnefurcht - um público mais maduro ("ab 10 Jahren"). ${ }^{49}$ Das três narrativas, esta é a que resgata de forma mais direta a literatura medieval

\footnotetext{
${ }^{46}$ No original: "Keine Ritter wollte je wieder mit dem Namemlosen kämpfen. Und Violetta heiratete den Rosengärtner ihres Vaters".

${ }^{47}$ No original: "Prinzessinen reiten und kämpfen nicht, Prinzesinnen sollen hübsch aussehen und mutige Ritter heiraten".

${ }^{48}$ No original: "Starke Mädchen wissen sich zu helfen!”.

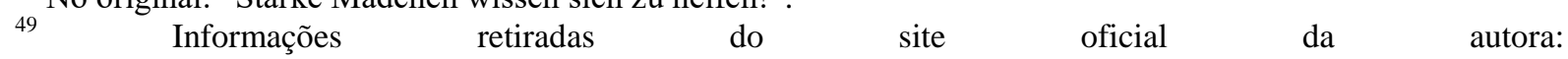
<http://www.corneliafunke.com/index.php?page=buecher\&lang=de $>$.
} 
Silva, D. G. - (Re)criação do medievo em Cornelia Funke

cortês, a começar pela escolha do nome da heroína - Igraine ${ }^{50}$ - e também por conta da jornada do herói.

Igraine, uma jovem que fará 12 anos, filha de Lamarok e Melisande (magos), inicia uma jornada para ajudar os pais a defender o burgo em que moram do ataque inimigo. Ao enfeitiçar o presente de aniversário da menina, os pais acabam por transformar-se em porcos e para conseguir desfazer o feitiço necessitam de cabelos de gigante, ingrediente em falta no burgo da família.

No dia de seu aniversário, Igraine recebe dos pais uma armadura encantada completa leve, cresceria juntamente com a menina e seria indestrutível (FunKE 2015: 41-42). O sonho de Igraine é tornar-se uma Riterrin, sonho compartilhado pelos pais. Embora os pais temam pela segurança da menina ao não querer que essa brinque com espadas de verdade (FUNKE 2015: 19), ao invés de forçar a menina a tornar-se uma maga como eles, alimentam seus sonhos ao presenteá-la com algo que faz parte desse desejo. Nas palavras de Igraine:

Amanhã completo 12 anos, Sisiphus!, prosseguiu Igraine, - 12! E ainda não vivi uma única aventura verdadeira. Como me tornarei, então, uma famosa 'caval(h)eira'? Devo salvar os coelhinhos das raposas ou proteger os esquilos das martas? ? $^{51}$ (FUNKE 2015: 17).

Ter 12 anos marca, assim, a entrada para a fase adulta e contrasta com a inexperiência em combates, visto que seu bisavô aos 7 anos já era escudeiro em torneios (FUNKE 2015: 18). A imagem da cavalaria introjetada pela menina prevê não apenas a fama, mas também as aventuras, ainda que estas estejam relacionadas ao universo infantil de Igraine: salvar coelhos e proteger esquilos.

A jornada de Igraine vai além da busca pelos cabelos do gigante; torna-se uma possibilidade de encontro com a verdadeira cavalaria, representada pela figura do "Cavaleiro Triste da Montanha das Lágrimas”52 (FunKE 2015: 89): uma cavalaria baseada em códigos de honra e conduta. É essa personagem que irá ensinar a jovem a manejar corretamente as armas e a se portar como um verdadeiro cavaleiro. Em um momento de treino corporal, o cavaleiro assevera: "Pensai sempre nas duas regras da cavalaria: nunca colocai vossa espada contra os

\footnotetext{
${ }^{50}$ Igraine, na literatura arturiana, é a mãe do grande herói Artur.

${ }^{51}$ No original: "Morgen bin ich zwölf, Sisiphus!", fuhr Igraine fort. "Zwölf! Und ich habe noch nicht ein einziges echtes Abenteuer erlebt. Wie soll ich so eine berühmte Ritterin werden? Soll ich Kaninchen vor dem Fuchs retten oder die Eichhörnchen vor den Mardern beschützen?".

${ }^{52}$ No original: "der Traurige Ritter vom Berg der Tränen". Mais adiante na narrativa descobre-se seu verdadeiro nome: "Urban von Wintergrün” (FUNKE 2015: 219).
} 
Silva, D. G. - (Re)criação do medievo em Cornelia Funke

mais fracos, mas somente para proteção, e - nunca a usai para vos enriquecer" ${ }^{\text {"53 }}$ (FUNKE 2015: 95), normas essas que remetem, em certa medida, à imagem da cavalaria cristã criada durante os séculos XII e XIII dentro da cultura cortês, principalmente no que tange a função de proteção àqueles que não o podem fazer (FLECKENSTEIN 2002: 188), ideias que se repetem no momento do confronto com o inimigo (Rowan Ohneherz):

São as regras da honra: protegei os fracos. Nunca cobiceis aquilo que pertence a outro. Usai de força e de armas somente no embate honesto. Nunca quebreis, nunca, vossa palavra empenhada. E não aspireis ao poder em nome do poder. Essas são as regras dos caval(h)eiros ${ }^{54}$ (FUNKE 2015: 188).

Todavia, dentre os topoi recorrentes acerca do ofício do cavaleiro é inserida uma nova informação - “[...] aquele que as cumprirem, seja homem ou donzela, a este será atribuída a honra, que lhe é devida" ${ }^{\circ 5}$ (FUNKE 2015: 188): também meninas podem se tornar cavaleiras se atentarem para essas regras. Neste contexto tornar-se um cavaleiro não está atrelado somente ao gênero, mas também à observância de regras e normas específicas. Por isso, Igraine pode se tornar uma Ritterin, caso aprenda a se comportar como tal, como afirma o Trauriger Ritter: "Vossa filha é destemida e de caráter mais cavaleiresco, ainda que ela, às vezes, interprete as regras cavaleirescas de uma forma diferente de mim" "56 (FUNKE 2015: 127).

Parte do treinamento é compreender que há a necessidade de saber avaliar a situação em que se encontra, principalmente no que se refere ao confronto com o adversário, como afirma o Trauriger Ritter para Igraine:

Vosso destemido coração vos honra. Contudo, por vezes, o destemor não é bom conselheiro. Devei aprender a temer algumas coisas e a avaliar corretamente vossas forças. Uma donzela de 12 anos, e tão brava, não pode de jeito algum confrontar-se com um cavaleiro tão experiente em combate quanto Rowan Sem Coração. Ele zombará de vós e esmagará vosso orgulho até tornar-se pó. ${ }^{57}$ (FUNKE 2015: 147-148)

\footnotetext{
${ }^{53}$ No original: "[...] denkt immer an die zwei Regeln des Rittertums: Setzt Eure Schwert nie gegen Schwächere ein, sondern nur zum Schutz, und - nutzt sie nie, um Euch zu bereichern".

${ }^{54}$ No original: "Es sind die Regeln der Ehre: Schützt die Schwachen. Begehrt nie, was einem anderen gehörtNutzt Kraft und Waffenkunst nur in ehrlichem Wettstreit. Brecht nie, niemals Euer gegebenes Wort. Und strebt nicht nach Macht um Macht willen. Das sind die Regeln des Ritters."

${ }^{55}$ No original: "[...] wer sie erfüllt, sei es ein Mann oder ein Mädchen, dem werde die Ehre zuteil, die ihm gebührt".

${ }_{56}$ No original: "Eure Tochter ist ohne Furcht und von ritterlichster Gesinnung, auch wenn sie die Ritterregeln bisweilen etwas anders auslegt als ich".

${ }^{57}$ No original: "Euer furchtloses Herz ehrt Euch. Aber manchmal ist Furchtlosigkeit kein guter Ratgeber. Ihr solltet lernen, vor einigen Dingen Angst zu haben und Eure Kräfte richtig einzuschätzen. Ein zwölfjähriges Mädchen, und sei es noch so tapfer, kann unmöglich gegen einen so kampferfahrenen Ritter wie Rowan Ohneherz antreten. Er wird Euch zum Gespött machen und Euren Stolz im Staub zertreten.”
} 
Silva, D. G. - (Re)criação do medievo em Cornelia Funke

Não somente a força e o treinamento são necessários para vencer o embate, mas também o intelecto: avaliar as possibilidades e as possíveis saídas. Sendo assim, o cavaleiro deixa explícito que há uma diferença entre "Rittersein", conceito ligado a códigos e condutas e que qualquer um pode alcançar, e "Ritter sein", faculdade exercida no corpo, ou seja, a necessidade da força bruta/muscular (JÜRGS 2012: 186).

\section{Considerações finais}

A concepção de Idade Média de Funke é uma espécie de "quimera", uma vez que une elementos historiográficos, literários, fantásticos, tanto medievais como pós-medievais, e desse amálgama resulta a criação dos universos temáticos que servem como pano de fundo para as suas obras: como se várias Idades Médias fossem evocadas em um mesmo espaço diegético. $^{58}$

Nas obras analisadas, notamos que a recepção do medievo ocorre em dois níveis complementares: 1. nível visual, pois há uma (re)criação imagética do medievo, e 2. nível textual, no qual há um diálogo estrutural (as jornadas dos heróis, nomes, valores cavaleirescos) com textos oriundos da literatura cortês medieval. Ambos os níveis, ao serem observados, apresentam uma releitura contemporânea desse passado, ou seja, uma presentificação do passado. No lugar dos cavaleiros corteses, encontramos "cavaleiras". Essa escolha por personagens femininas e jovens no lugar das masculinas, genderswapping, possibilita uma maior identificação com um público leitor de meninas e dialoga com novas configurações de gênero (outras das factuais em relação ao medievo): Frieda tem astúcia, Violetta vence pela força adquirida com o treinamento, e Igraine une intelecto e treinamento.

As narrativas apresentam femininos que lutam, seja para salvar um masculino ou em causa própria (por si ou pela família), propondo, assim, novas configurações de heróis, mas se mantendo a estrutura da épica cortês no que tange à busca e o salvamento. Todavia, novas configurações de gênero dentro do discurso contemporâneo não são apresentadas de maneira consequente nas narrativas, pois em Die geraubten Prinzen e em Der geheimnissvolle Ritter Namenlos retorna-se ao lugar comum do casamento entre masculino e feminino. Em Igraine Ohnefurcht, trata-se do processo de amadurecimento, "do reconhecimento e da aceitação das

\footnotetext{
${ }^{58}$ Agradecemos, para essa passagem, a contribuição de Maurício da Cunha Albuquerque.
} 
Silva, D. G. - (Re)criação do medievo em Cornelia Funke

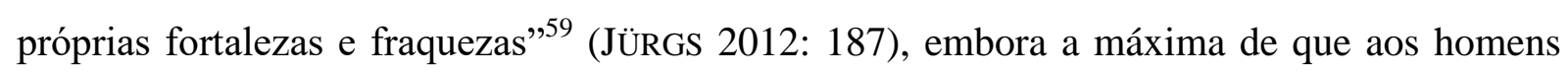
pertence a força bruta seja reiterada.

Asseveramos, ainda, que as questões relativas ao gênero parecem subjazer às narrativas, visto que estas possibilitam a inserção de femininos como protagonistas de suas próprias histórias: meninas também podem ser valentes e vencer demandas, seja pela astúcia ou pelo treinamento. Aqui fica nítida a apropriação da temática "cavalaria cortês" e sua recriação/atualização na inserção de figuras femininas no espaço de protagonismo. Se na épica cortês a personagem masculina nasce predestinada a se tornar cavaleira, necessitando apenas de treinamento adequado (veja o caso de Parzival), nas narrativas de Funke, há uma diferença perceptível entre sein e werden, pois as protagonistas se tornam Ritterinnen pelo intelecto e pelo treinamento. Neste sentido, essas narrativas mostram personagens femininas que se encaixam na lógica emancipatória do feminino; são apresentadas, portanto, mulheres jovens, fortes e das quais as representações distam do topos tradicional dos femininos encontrados em contos de fadas mais ligados à tradição.

Nos dois níveis analisados (imagem e narrativa), percebemos que a recepção do medievo se dá através de atualizações (por exemplo o protagonismo feminino), mostrando-se, portanto, como um meio para compreender novas configurações sociais, ou seja, as presentificações de um passado. Em um presente que, cada vez mais, se configura como espaço de rediscussão de valores tidos como absolutos, uma literatura que lança mão de um imaginário recorrente (veja-se o boom de releituras medievais na atualidade) para representar protagonistas femininas deve ser vista dentro do seu potencial educador e renovador.

\section{Referências}

ANKERSMIT, Frank. Verdade na história e na literatura. In: A escrita da história: a natureza da representação histórica. Tradução de Jonathan Menezes. Londrina: Eduel, 2012. p. 269-302.

BöCKEM, Jörg. Ich habe einen Traum: "Einmal auf einem Drachen reiten". Interview mit Cornelia Funke. Die Zeit, n. 52, 17 dez. 2008. Disponível em: <http://www.zeit.de/2008/52/TraumFunke-52/komplettansicht>. Acesso em: 16 jul. 2016.

BRANDT, Rüdiger. Grundkurs germanistische Mediävistik: Literaturwissenschaft. München: Wilhelm Fink, 1999.

BUMKE, Joachim. Geschichte der deutschen Literatur im hohen Mittelalter. München: DTV, 2000.

\footnotetext{
${ }^{59}$ No original: “[...] das Erkennen und Akzeptieren der eigenen Stärken und Schwächen”.
} 
Silva, D. G. - (Re)criação do medievo em Cornelia Funke

Cornelia Funke Pressmape. 2015. Disponível em: <http://www.dresslerverlag.de/fileadmin/verlagsgruppe-oetinger.de/pdf/autoren/3258.pdf >. Acesso em: 14 jul. 2016.

Cossham, Lisa Frieda. »Man kann nicht alles allein schaffen«. Interview mit Cornelia Funke. Süddeutsche Zeitung, n. 10, 2013. Disponível em: < $\underline{\text { http://sz- }}$ magazin.sueddeutsche.de/texte/anzeigen/39621>. Acesso em: 16 jul. 2016.

ECKMANN-SCHMECHTA, Stefanie. Interview mit Cornelia Funke. Kinderbuch-couch, 2005. Disponível em: <http://www.kinderbuch-couch.de/interview-cornelia-funke.html $>$. Acesso em: 16 jul. 2016.

FLECKENSTEIN, Josef. Rittertum und ritterliche Welt. Berlin: Siedler, 2002.

FREUND, Wieland. Gespräche mit Cornelia Funke. Die einflußreichste Deutsche der Welt. Die Welt On Line, 15 abr. 2005. Disponível em: <http://www.welt.de/print-welt/article661155/Dieeinflussreichste-Deutsche-der-Welt.htmle>. Acesso em: 14 jul. 2016.

FunKe, Cornelia. Coração de tinta. Tradução de Sonali Bertuol. São Paulo: Companhia das Letras, 2006.

FUnKE, Cornelia. Der geheimnisvolle Ritter Namenlos. Frankfurt am Main: Fischer, 2001.

FunKE, Cornelia. Der Namenlose Ritter. In:___ Leselöwen: Rittergeschichten. Bindlach: Loewe, 1994a. p. 18-25.

FunKe, Cornelia. Die geraubten Prinzen. Hamburg: Carlsen, 2014.

FUnKE, Cornelia. Die geraubten Prinzen. In:___. Leselöwen: Rittergeschichten. Bindlach: Loewe, 1994b. p. 26-33.

FUNKE, Cornelia. Igraine Ohnefurcht. Hamburg: Dressler, 2015.

FUnKE, Cornelia. Tintenherz. 2. ed. Hamburg: Oetinger, 2010.

GASCHKE, Susanne. Cornelia Funke: Erzählen für alle. Die Zeit, n. 48, 20 nov. 2008. Disponível em: <http://www.zeit.de/2008/48/KJ-Interview-Funke/komplettansicht〉. Acesso em: 6 ago. 2016.

GoETZ, Hans-Werner. Einführung: Die Gegenwart des Mittelalters und die Aktualität der Mittelalterforschung. In: (Org.). Die Aktualität des Mittelalters. Bochum: Dr. Dieter Winkler, 2000. p. 7-23.

GROEBNER, Valentin. Das Mittelalter hört nie auf. Über historisches Erzählen. München: C. H. Beck, 2008.

HERwEG, Mathias; KePPLER-TASAKI, Stefan. Mittelalterrezeption. Gegenstände und Theorienansätze eines Forschungsgebiets im Schnittpunkt von Mediävistik, Frühneuzeit- und Modernforschung. In: (Org.). Rezeptionskulturen. Fünfhundert Jahre literarischer Mittelalterrezeption zwischen Kanon und Populärkultur. Berlin: Walter de Gruyter, 2012. p. 112.

ISER, Wolfgang. Os atos de fingir ou o que é fictício no texto ficcional. In: LiMA, Luiz Costa (Org.). Teoria da literatura em suas fontes. 2. ed. Rio de Janeiro: Francisco Alves, 2002. v. 2, p. 955987.

JÜRGS, Jana. „Tragt Rüstung mit dem Artuswappen, dann wird's auch mit dem Drachen klappen!“ Mittelalter(-darstellung) in Kinder- und Jugendbüchern. In: BENNEWITZ, Ingrid; SCHINDLER, Andrea (Org.). Mittelalter im Kinder- und Jugendbuch. Akten der Tagung Bamberg 2010. Bamberg: University of Bamberg Press, 2012. p. 177-196.

KARG, Ina. Ritter, Elfen, Zauberwelten. Mittelalterbilder in aktuellen Kinder- und Jugendliteratur. In: MERTENS, Volker; STANGE, Carmen (Org.). Bilder vom Mittelalter. Göttingen: Vandenhoeck \& Ruprecht, 2007. p. 155-179.

KöHN, Rolf. Was ist und soll eine Geschichte der Mittelalterrezeption? Thesen eines Historikers. In: BuRG, Irene et al. (Org.). Mittelalter-Rezeption IV: Medien, Politik, Ideologie, Ökonomie. Göppingen: Kümmerle, 1991. p. 407-431.

LE Goff, Jacques. Heróis e maravilhas da Idade Média. Tradução de Stephania Matousek. Petrópolis: Vozes, 2011. 
Silva, D. G. - (Re) criação do medievo em Cornelia Funke

LE GuIN, Ursula K. The Language of the Night: Essays on Fantasy and Science Fiction. New York: Harper Collins, 1993.

Lewis, Michael J; Owen-Crocker, Gale L.; Terkla, Dan (Org.). The Bayeux Tapestry: New Approaches. Oxford: Oxbow Books, 2011.

MACEDO, José Rivair. Introdução - Cinema e Idade Média: perspectivas de abordagem. In: MACEDO, José Rivair; Mongelli, Lênia Márcia (Org.). A Idade Média no cinema. São Paulo: Ateliê Editorial, 2009. p. 13-48.

MÄRTL, Claudia. Einheit und Vielfalt. Von der Aktualität des Mittelalters. Braunschweig: Technische Universität, 1997.

OeXle, Otto Gerhard. Das entzweite Mittelalter. In: Althoff, Gerd (Org.). Die Deutschen und ihr Mittelalter: Themen und Funktionen moderner Geschichtsbilder vom Mittelalter. Darmstadt 1992. p. 7-28.

PICHLER, Madeleine. Die Rezeption der Kinder- und Jugendbuchautorin Cornelia Funke im deutschen und englischen Sprachraum. Diplomarbeit. Wien: Universität Wien, 2011. Disponível em: <http://othes.univie.ac.at/14774/1/2011-05-23 0401826.pdf>. Acesso em: 17 jul. 2016.

PÖGE-ALDER, Kathrin. Märchenforschung: Theorien, Methoden, Interpretationen. Tübingen: Narr, 2011.

SAFRANSKI, Rüdiger. Romantik: eine deutsche Affüre. Frankfurt am Main: Fischer, 2009.

ScHNITH, Karl. Bayeux, Teppich von. [1] Allgemein. In: Lexikon des Mittelalters. München: DTV, 2003, vol. 1, p. 1712.

SCOTT, Joan Wallach. Gender: A Useful Category of Historical Analysis. In: Gender and the Politics of History. New York: Columbia University Press, 1999. 28-50.

SILVA, Daniele Gallindo Gonçalves. Para uma (re)mitificação dos Nibelungen no período entre Guerras Mundiais. Literatura e Autoritarismo (UFSM), v. 1, p. 61-79, 2014. Disponível em: $<$ http://cascavel.ufsm.br/revistas/ojs-2.2.2/index.php/LA/article/view/13078/pdf $>$. Acesso em: 2 fev. 2016.

SPRECKELSEN, Tilman. Im Gespräch: Cornelia Funke. Das Fell einer Füchsin oder eine Haut aus Stein. Frankfurter Allgemeine - Feuilleton, 13 set. 2010. Disponível em: $<$ http://www.faz.net/aktuell/feuilleton/buecher/autoren/im-gespraech-cornelia-funke-das-felleiner-fuechsin-oder-eine-haut-aus-stein11040698.html?printPagedArticle=true\#pageIndex 2>. Acesso em: 16 jul. 2016.

STEHLE, Julia. Moderne Literatur und die Philosophie des Mittelalters. Joyce, Beckett, Andersch, mit einer Einführung in die Mittelalterrezeption. Marburg: Tectum, 2012.

ZILM, Kerstin. Cornelia Funke „SPARK“ Ausstellung in Los Angeles: Inspiration im digitalen Zeitalter. Deutschlandfunk, 20 fev. 2015. Disponível em: $<$ http://www.deutschlandfunk.de/cornelia-funke-spark-ausstellung-in-los-angelesinspiration.807.de.html?dram:article_id=312192>. Acesso em: 14 jul. 2016. 